\title{
Phytochemical Composition and Antioxidant Potential of Ruta graveolens L. In Vitro Culture Lines
}

\author{
Renuka Diwan, Amit Shinde, and Nutan Malpathak \\ Department of Botany, University of Pune, Pune Maharashtra 411007, India \\ Correspondence should be addressed to Nutan Malpathak, mpthak@unipune.ac.in
}

Received 20 July 2011; Accepted 14 January 2012

Academic Editor: Gaoming Jiang

Copyright () 2012 Renuka Diwan et al. This is an open access article distributed under the Creative Commons Attribution License, which permits unrestricted use, distribution, and reproduction in any medium, provided the original work is properly cited.

Ruta graveolens L. is a medicinal plant used in traditional systems of medicine for treatment of psoriasis, vitiligo, leucoderma, and lymphomas with well-known anti-inflammatory and anticancer properties. Therefore antioxidant potential of $R$. graveolens (in planta and in vitro) was investigated. As antioxidants present in plant extracts are multifunctional, their activity and mechanism depends on the composition and conditions of the test system. Therefore, the total antioxidant capacity was evaluated using assays that detect different antioxidants: free radical scavenging (DPPH and ABTS), transition metal ion reduction (phosphomolybdenum assay), reducing power, and nitric oxide reduction. Content of furanocoumarin-bergapten in the extracts showed good corelation with free radical scavenging, transition metal reduction and reducing power, while total phenolic content showed good corelation with nitric oxide reduction potential. Antioxidant activity of in vitro cultures was significantly higher compared to in vivo plant material. The present study is the first report on comprehensive study of antioxidant activity of $R$. graveolens and its in vitro cultures.

\section{Introduction}

Free radicals, together with secondarily formed radicals, are known to play an important role in the pathogenesis of many chronic conditions like atherosclerosis, arthritis, diabetes, ischemia, reperfusion injuries, central nervous system injury, and cancer $[1,2]$. Hence, the study of antioxidant status during a free radical challenge can be used as an index of protection against the development of these degenerative processes in experimental condition for therapeutic measures.

Ruta graveolens is used in homeopathic, ayurvedic, and unani preparations [3] because this herb is so efficacious in various diseases (Ruta derived from Greek "reuo" means to set free). It has been extensively used in treatment of leucoderma, vitiligo, psoriasis, multiple sclerosis, cutaneous lymphomas, rheumatic arthritis and recently reported to possess anti-inflammatory and anticancer activity [4, 5]. Antioxidants in plants are affected by area, climatic conditions, and pest attack $[6,7]$; therefore in vitro cultures are being investigated as alternate source of natural antioxidants [8]. For estimation of total antioxidant potential many authors have stressed the need to perform more than one type of antioxidant activity measurement to take into account the various mechanisms of antioxidant action [9]. With this perspective the present study investigates the total antioxidant activity evaluated using DPPH, ABTS, phosphomolybdenum complex, reducing power, and Nitric oxide reduction assay of six selected culture lines of $R$. graveolens. Correlation between activity and phytochemical composition of extract (for total phenolics, flavonoids, flavonols, and furanocoumarin) was determined. To our knowledge, the present study is the first report on comprehensive study of antioxidant activity of $R$. graveolens and its in vitro cultures.

\section{Methodology}

2.1. Plant Material. Fruits, shoots, and roots were obtained from Ruta graveolens L. (Rutaceae) plants grown in Botanic garden, Department of Botany, University of Pune.

2.2. In Vitro Cultures. Three cell culture lines with varying degree of differentiation (dispersed cell line RC1, 
aggregated cell line RC3 and differentiated cell line RC6) [10] were selected for evaluating antioxidant potential. Shoot line RS2 [11] and genetically transformed clone Ia3 (Manuscript under revision by Acta Physiologiae Plantarum) were selected due to their lower doubling time and high furanocoumarin productivity.

2.3. Preparation of Extracts. In vivo fruits, shoots, and roots were used as reference. Finely pulverized plant material $(100 \mathrm{mg})$ was cold-extracted in ultrapure methanol overnight and centrifuged at 10,000 rpm for $20 \mathrm{~min}$ and supernatant was filtered. Supernatant was evaporated to dryness at room temperature and dissolved in methanol (ultrapure) to achieve final concentration of $1 \mathrm{mg} / \mathrm{mL}$.

2.4. Phytochemical Composition. Estimation of total phenolic, flavonoids, flavanols, and furanocoumarins. Total phenols were estimated as gallic acid equivalents (GAEs), expressed as $\mathrm{mg}$ gallic acid/g extract by Singleton et al. [12]. The content of flavonoids was determined by method described by Miliauskas et al. [6] using rutin as a reference compounds. The amount of flavonoids in plant extracts was expressed in rutin equivalent (RE). The flavonols content was determined by Miliauskas et al. [6] method. The content of flavanols was expressed in rutin equivalents (REs) as described above. Furanocoumarins psoralen, bergapten, and xanthotoxin were extracted and estimated according to method described elsewhere [11].

\subsection{Antioxidant Activity}

(1) $D P P H$. Free radical scavenging estimated according to Szabo et al. [13].

(2) ABTS. The free radical scavenging was measured by method of Teow et al. [14].

(3) Phosphomolybdenum Reduction. The total antioxidant capacity of extracts was evaluated by method of Prieto et al. [15] and expressed as equivalents of ascorbic acid ( $\mu \mathrm{mol} / \mathrm{g}$ of extract).

(4) Reducing Power. It was determined using method described by Oyaizu [16].

(5) Nitric Oxide Scavenging Activity. The nitric oxide scavenging activity was measured according to the method described by Marcocci et al. [17].

2.6. Statistical Analysis. The influence of various treatments on growth and phytochemical content was analyzed by oneway analysis of variance (ANOVA). Free radical scavenging activity (DPPH and ABTS), reduction of transition metal ions by phosphomolybdenum complex, reducing power, nitric oxide reduction assay, and total phenolics, flavonoids and flavonols were determined in triplicates.

\section{Results and Discussions}

3.1. Phytochemical Composition of In Vitro Lines. Plant phenolics constitute one of the major groups of compounds acting as primary antioxidants or free radical scavengers. Flavonoids are one of the most diverse and widespread group of natural compounds and are one of the most important natural phenolics. These compounds possess a broad spectrum of activities including radical scavenging properties [7]. Therefore it was necessary to determine total amounts of phenolics, flavonoids, and flavanols in the selected extracts.

In vivo root extracts has the highest phenolic content (80 mg GAE/g dry wt). In vivo shoot extracts showed lower phenolic content (37 mg GAE/g dry wt) as compared to in vitro shoot line RS2 (41 mg GAE/g dry wt) and transformed shoot clone Ia3 (50 mg GAE/g dry wt) (Figure 1(a)). The total flavanoid content in the in vivo plant extract ranged from 0.4 to $0.8 \mathrm{mg} / \mathrm{g}$ plant extract in $\mathrm{RE}$, whereas total flavanoid content in the in vitro cultures ranged from 1 to $17.7 \mathrm{mg} / \mathrm{g}$ plant extract (Figure 1(b)). In vitro shoot cultures showed 2.18-fold increase in flavanoid content as compared to in vivo shoots. The total flavanol content in the in vivo plant extract ranged from 0.36 to $0.68 \mathrm{mg} / \mathrm{g}$ plant extract in $\mathrm{RE}$, whereas total flavanol content in the in vitro cultures ranged from 0.5 to $2.4 \mathrm{mg} / \mathrm{g}$ plant extract (Figure $1(\mathrm{~b})$ ).

Furanocoumarins are one of the main active constituents of Ruta graveolens and are also reported to be potent antioxidants [18, 19]. Potent antioxidant activity (DPPH, APPH) of Angelica dahuricae extracts was attributed to the furanocoumarins [20]. Therefore amount of psoralen, bergapten, and xanthotoxin in the extracts were determined (Figure 1(c)). Fruits showed highest furanocoumarins content in planta. Amongst in vitro cultures differentiation dependent accumulation of bergapten and xanthotoxin was seen $[11,12]$ with high bergapten and xanthotoxin accumulation in culture lines RC5, RS2, and Ia3, and high psoralen accumulation in RC1 and RC3 (Figure 1(c)).

\subsection{Antioxidant Activity}

3.2.1. DPPH Radical Scavenging Activity. The radical scavenging activity was expressed as percentage of reduction of initial DPPH absorbance by the extracts at different concentrations (Figure 2). In vitro culture extracts, shoot line RS2, and transformed line Ia3 showed highest radical scavenging activity of $86.4 \%$ and $89.1 \% \quad\left(\mathrm{EC}_{50}: 33\right.$ and $60 \mu \mathrm{g} / \mathrm{mL}$ ), respectively, as compared to $50 \%$ and $64 \%$ $\left(\mathrm{EC}_{50}: 400,130 \mu \mathrm{g} / \mathrm{mL}\right.$ ) inhibition by roots and shoots. The percentages can be considered as full absorption inhibition of DPPH, because after completion of reaction the final solution always possesses some yellowish colour and therefore its absorption inhibition compared to colourless methanol solutions cannot reach $100 \%$ as shown by Miliauskas et al. [6].

3.2.2. ABTS $^{+}$Radical Scavenging Activity. Amongst all extracts tested, highest antioxidant potential was shown by 


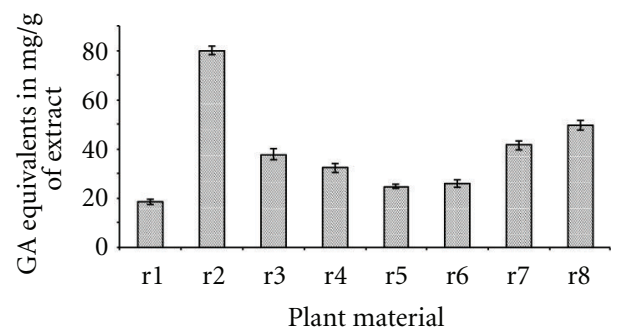

Total phenolic content

(a) Total phenolic content in in vivo and in vitro cultures of $R$. graveolens
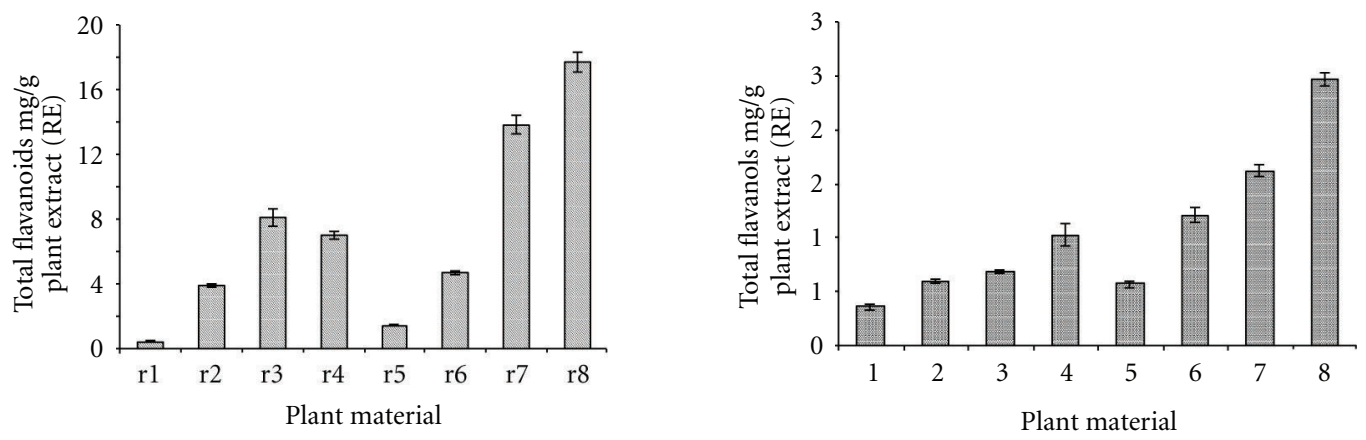

(b) Total flavanoids and flavanols in in vivo and in vitro cultures of $R$. graveolens

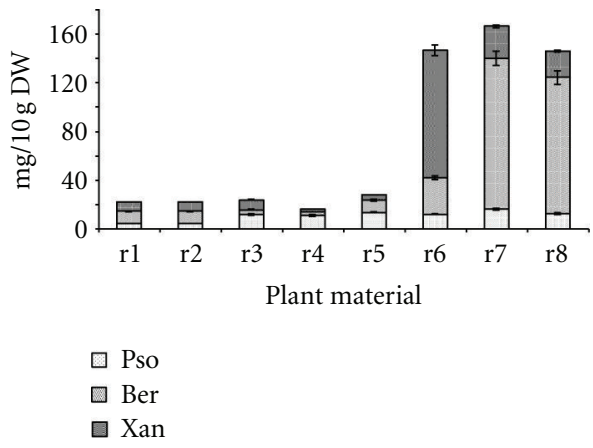

(c) furanocoumarins in in vivo and in vitro cultures of $R$. graveolens

FIgURE 1: Values are mean of three replicates \pm std. dev. values significant at $P \leq 0.095$ as calculated by two-way Anova (VassarStats), r1 = in vivo fruits, $\mathrm{r} 2=$ in vivo roots, $\mathrm{r} 3=$ in vivo shoots, $\mathrm{r} 4=$ dispersed suspension $\mathrm{RC} 1, \mathrm{r} 5=$ aggregated suspension $\mathrm{RC} 3$, $\mathrm{r} 6=$ differentiated suspension RC5, r7 = shoot line RS2, r8 = transformed clone Ia3.

TABLE 1: Correlation analysis.

\begin{tabular}{lcccccc}
\hline Antioxidant activity & Phenolics & Flavanols & Flavanoids & Psoralen & Bergapten & Xanthotoxin \\
\hline DPPH & 0.433 & 0.089 & 0.124 & 0.407 & $\mathbf{0 . 7 7 9}$ & 0.150 \\
ABTS & 0.248 & 0.105 & 0.047 & 0.571 & $\mathbf{0 . 8 6 5}$ & 0.111 \\
Phosphomolybdenum assay & 0.221 & 0.388 & 0 & 0.221 & $\mathbf{0 . 7 0 4}$ & 0.384 \\
Reducing power & 0.163 & $\mathbf{0 . 5 1 8}$ & 0.399 & 0.090 & $\mathbf{0 . 5 7 8}$ & 0.151 \\
Nitric oxide reduction & $\mathbf{0 . 8 3}$ & 0.34 & 0.23 & 0.42 & 0.213 & 0.287 \\
\hline
\end{tabular}

shoot line RS2 and transformed line Ia3 (EC50; 65 and $115 \mu \mathrm{g} / \mathrm{mL}$ ), respectively (Figure 3).

Comparing results of the two radical scavenging tests (DPPH:ABTS) showed good correlation between their activity $\left(r^{2}=0.98\right)$.
3.2.3. Phosphomolybdenum Assay. The different extracts at a concentration of $(50 \mu \mathrm{g} / \mathrm{mL})$ were assayed for their antioxidant potency by the formation of green phosphomolybdenum complex (Figure 4). In vitro shoots line RS2 and transformed clone Ia3 extract had strongest effects on 

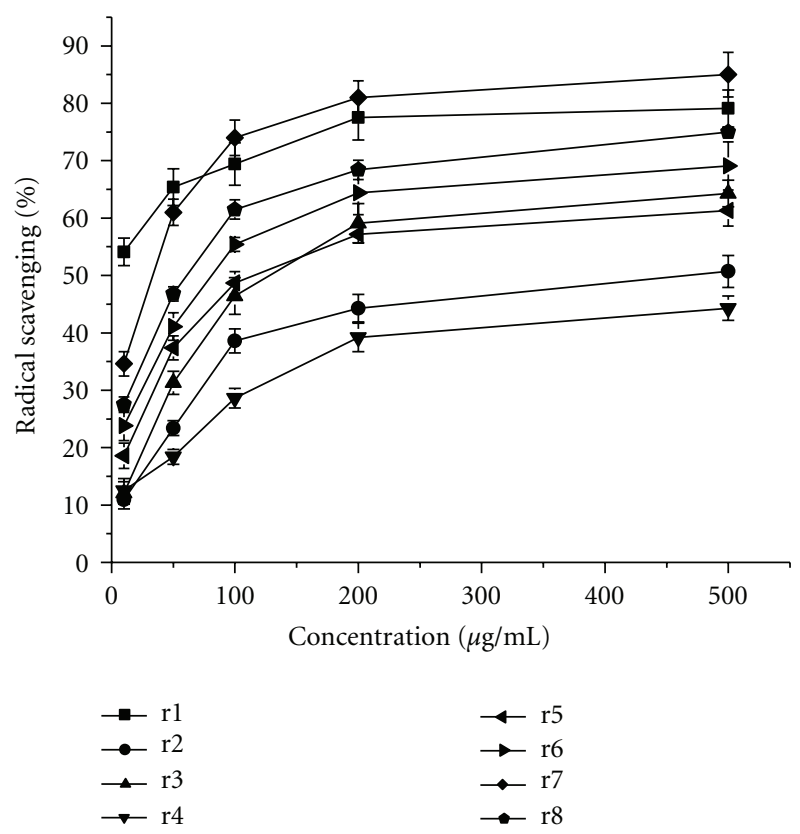

FIGURE 2: DPPH radical scavenging activity of $R$. graveolens in vivo and in vitro cultures. Values are mean of three replicates \pm std. dev. values significant at $P \leq 0.095$ as calculated by two-way Anova (VassarStats), $\mathrm{r} 1=$ in vivo fruits, $\mathrm{r} 2=$ in vivo roots, $\mathrm{r} 3=$ in vivo shoots, $\mathrm{r} 4=$ dispersed suspension $\mathrm{RC} 1, \mathrm{r} 5=$ aggregated suspension RC3, r6 = differentiated suspension RC5, r7 = shoot line RS2, r8 = transformed clone Ia3.

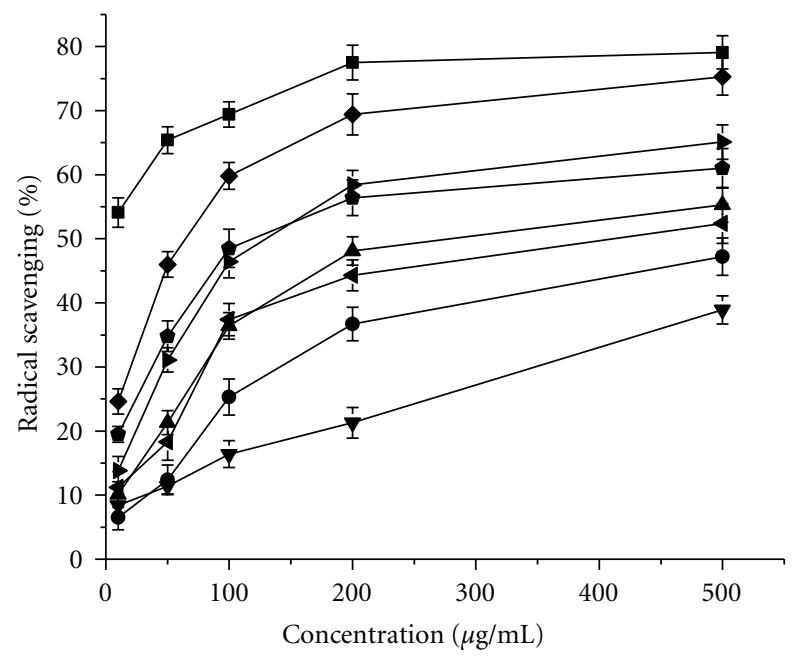

$$
\begin{array}{ll}
\rightarrow \mathrm{r} 1 & \hookrightarrow \mathrm{r} 5 \\
\rightarrow \mathrm{r} 2 & \rightarrow \mathrm{r} 6 \\
\multimap \mathrm{r} 3 & \rightarrow \mathrm{r} 7 \\
\rightarrow \mathrm{r} 4 & \rightarrow \mathrm{r} 8
\end{array}
$$

FIgURE 3: ABTS radical scavenging activity of $R$. graveolens in vivo and in vitro cultures. Values are mean of three replicates \pm std. dev. values significant at $P \leq 0.095$ as calculated by two way Anova (VassarStats), $\mathrm{r} 1=$ in vivo fruits, $\mathrm{r} 2=$ in vivo roots, $\mathrm{r} 3=$ in vivo shoots, $\mathrm{r} 4=$ dispersed suspension $\mathrm{RC} 1, \mathrm{r} 5=$ aggregated suspension RC3, r6 = differentiated suspension RC5, r7 = shoot line RS2, r8 = transformed clone Ia3.

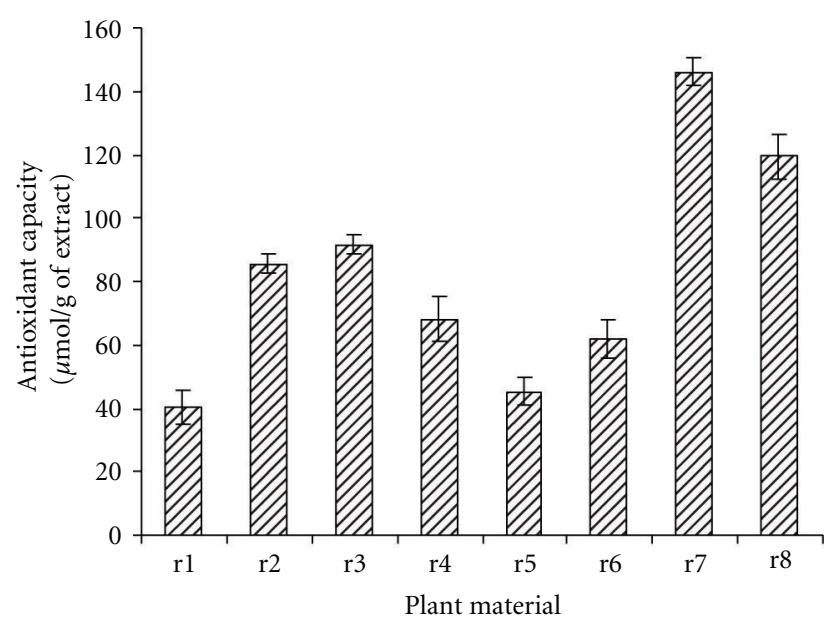

$\square$ Antioxidant capacity

FIgure 4: Phosphomolybdenum assay of in vivo and in vitro culture extracts of $R$. graveolens. Values are mean of three replicates \pm std. dev. values significant at $P \leq 0.095$ as calculated by two way Anova (VassarStats), $\mathrm{r} 1=$ in vivo fruits, $\mathrm{r} 2=$ in vivo roots, $\mathrm{r} 3=$ in vivo shoots, $\mathrm{r} 4=$ dispersed suspension $\mathrm{RC} 1, \mathrm{r} 5=$ aggregated suspension $\mathrm{RC} 3, \mathrm{r} 6$ = differentiated suspension RC5, r7 = shoot line RS2, r8 = transformed clone Ia3.

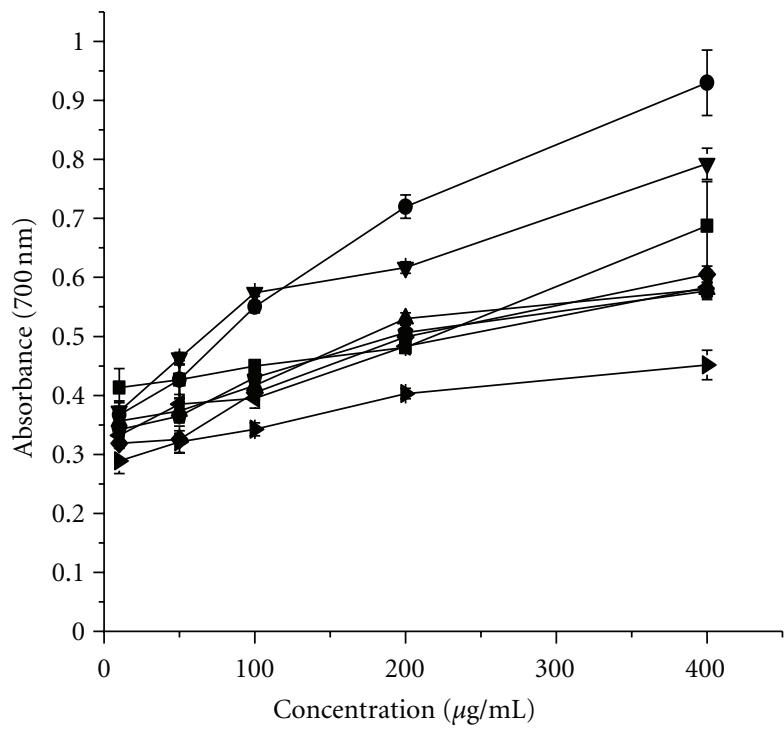

$$
\begin{array}{ll}
\because \mathrm{r} 1 & \leftarrow \mathrm{r} 5 \\
\rightarrow \mathrm{r} 2 & \rightarrow \mathrm{r} 6 \\
\leftarrow \mathrm{r} 3 & \rightarrow \mathrm{r} 7 \\
\rightarrow \mathrm{r} 4 & \rightarrow \mathrm{r} 8
\end{array}
$$

Figure 5: Reducing power in vivo and in vitro culture extracts of $R$. graveolens. Values are mean of three replicates \pm std. dev. values significant at $P \leq 0.095$ as calculated by two way Anova (VassarStats), $\mathrm{r} 1=$ in vivo fruits, $\mathrm{r} 2=$ in vivo roots, $\mathrm{r} 3=$ in vivo shoots, $\mathrm{r} 4=$ dispersed suspension $\mathrm{RC} 1, \mathrm{r} 5=$ aggregated suspension $\mathrm{RC} 3, \mathrm{r} 6$ = differentiated suspension RC5, r7 = shoot line RS2, r8 = transformed clone Ia3. 


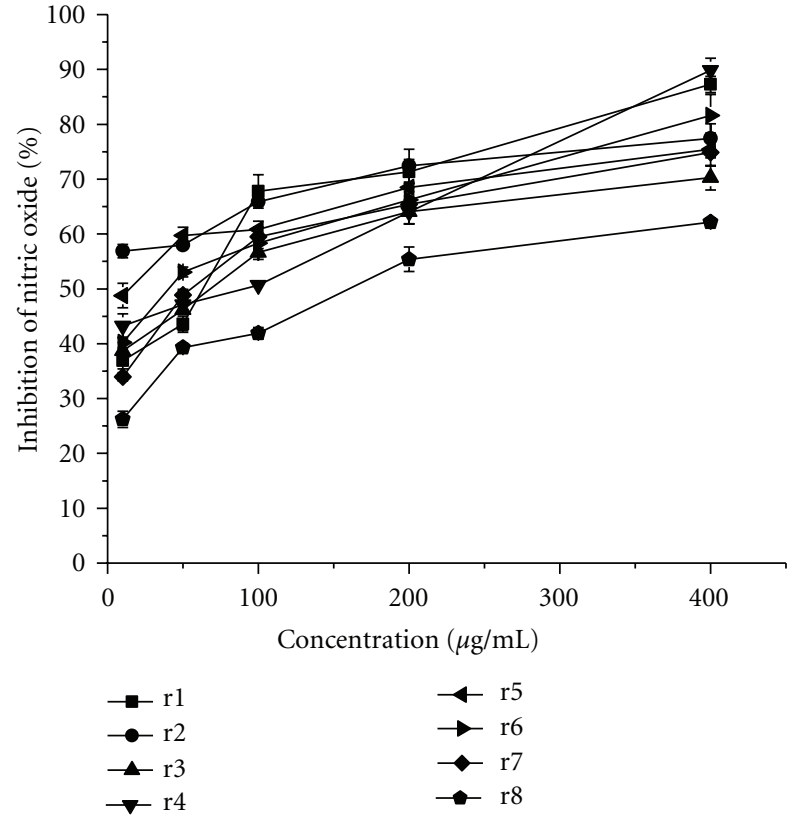

Figure 6: Percentage inhibition of nitric oxide radicals by $R$. graveolens in vivo and in vitro cultures extracts. Values are mean of three replicates \pm std. $\mathrm{dev}$. values significant at $P \leq 0.095$ as calculated by two-way Anova (VassarStats), $\mathrm{r} 1=$ in vivo fruits, $\mathrm{r} 2=$ in vivo roots, $\mathrm{r} 3=$ in vivo shoots, $\mathrm{r} 4=$ dispersed suspension $\mathrm{RC} 1, \mathrm{r} 5$ = aggregated suspension RC3, r6 = differentiated suspension RC5, $\mathrm{r} 7=$ shoot line RS2, r8 = transformed clone Ia3.

reducing Mo radical (146, 119 equivalents of ascorbic acid $\mu \mathrm{mol} / \mathrm{g}$ of extract, resp.) which was 1.5 -fold higher than in vivo shoots $(91 \mu \mathrm{mol}$ ascorbic acid/g).

It is known that hydrogen and electron transfer from antioxidant analytes to $\mathrm{DPPH}^{-}, \mathrm{ABTS}^{+}$and $\mathrm{Mo}(\mathrm{VI})$ complex occur in the DPPH, $\mathrm{ABTS}^{+}$and phosphomolybdenum assay methods. The transfers occur at different redox potentials in the two assays and also depend on the structure of the antioxidant. $\mathrm{DPPH}^{-}$and $\mathrm{ABTS}^{+}$scavenging assays detect antioxidants such as flavonoids and polyphenols, whereas the phosphomolybdenum method usually detects antioxidants such as ascorbic acid, some phenolics, atocopherol, and carotenoids [15]. Ascorbic acid, glutathione, cysteine, tocopherols, polyphenols, and aromatic amines can be detected by the two assay models [21]. Thus the antioxidant potential of the extracts differed in these two types of assays. Fruit extracts which showed highest $\mathrm{DPPH}^{-}$ and $\mathrm{ABTS}^{+}$scavenging activity $\left(\mathrm{EC}_{50}: 9 \mu \mathrm{g} / \mathrm{mL}\right)$ showed lowest antioxidant potential in the phosphomolybdenum assay (50 equivalents of ascorbic acid $\mu \mathrm{mol} / \mathrm{g}$ of extract). From correlation analysis it was seen that bergapten content showed good correlation with DPPH $\left(r^{2}=078\right)$, ABTS $\left(r^{2}=\right.$ $0.86)$ and phosphomolybdenum assay $\left(r^{2}=0.7\right)$ (Table 1$)$.

3.2.4. Reducing Power Assay. Dose-dependant increase in reducing power of $\mathrm{Fe}^{3+}$ to $\mathrm{Fe}^{2+}$ was observed in the extracts (Figure 5). Amongst all extracts tested, highest activity was observed for root extract (absorbance of 0.93 at $400 \mu \mathrm{g} / \mathrm{mL}$ ).
Dispersed suspension (RC1) extract $(400 \mu \mathrm{g} / \mathrm{mL})$ showed maximum absorbance (0.81) amongst all the in vitro cultures tested. No significant difference was observed between in vitro shoot cultures and in vivo shoots. Reducing power of BHT was observed to be 0.8 at $1 \mathrm{mg} / \mathrm{mL}$. It was seen that reducing power showed partial correlation with total flavanol $\left(r^{2}=0.51\right)$ and bergapten $\left(r^{2}=0.58\right)$ content.

3.2.5. Nitric Oxide Scavenging Activity. Dose-dependant increase in nitric-oxide radical scavenging activity was observed at studied concentrations (Figure 6). Highest activity was showed by in vivo root extracts $\left(\mathrm{EC}_{50}: 10 \mu \mathrm{g} / \mathrm{mL}\right.$ ). Amongst in vitro cultures, aggregated cell suspension culture RC3 showed highest activity $\left(\mathrm{EC}_{50}: 13.1 \mu \mathrm{g} / \mathrm{mL}\right)$ followed by differentiated cell suspensions RC5 and dispersed cell suspensions RC1 $\left(\mathrm{EC}_{50}: 41.8\right.$ and $\left.93.9 \mu \mathrm{g} / \mathrm{mL}\right)$, respectively. $\mathrm{EC}_{50}$ of Butylated hydroxyl toluene (BHT) was $>300 \mu \mathrm{g} / \mathrm{mL}$, which is considerably higher than that of $R$. graveolens extracts. Thus in vivo and in vitro extracts of $R$. graveolens are potent scavengers of NO radicals. Nitric oxide reducing ability showed good correlation with total phenolic content $\left(r^{2}=0.83\right)$ of the extracts.

Results obtained here showed that extracts from in vitro cultures showed strong antioxidant activity (DPPH, ABTS, reducing power, phosphomolybdenum assay) as compared to in vivo plant material. It has been reported that dedifferentiated cultures (callus and suspension) have less antioxidant potential [22]. However, our results indicated good antioxidant potential (reducing power and nitric oxide scavenging) of $R$. graveolens cell suspension. The observed elevated activity of in vitro cultures can be attributed to furanocoumarins especially bergapten and phenolics (Table 1 ) [23].

Production of antioxidants through plant tissue cultures is an effective strategy which also offers additional advantage of optimization of production of these agents by changing culture conditions and production of active antioxidant principles throughout year [9]. Present study highlighted the use of in vitro cultures as a source of antioxidants. Collectively, furanocoumarin content and antioxidant activities of $R$. graveolens will help to select suitable culture type as a source of natural antioxidants and nutraceuticals to enhance health benefits.

\section{Acknowledgment}

The financial support provided by University Grants Commission (UGC), New Delhi, India is duly acknowledged. All authors contributed equally to this work.

\section{References}

[1] N. C. Cook and S. Samman, "Flavonoids-Chemistry, metabolism, cardioprotective effects, and dietary sources," Journal of Nutritional Biochemistry, vol. 7, no. 2, pp. 66-76, 1996.

[2] J. T. Kumpulainen and J. T. Salonen, Natural Antioxidants and Anticarcinogens in Nutrition, Health and Disease, Royal Society of Chemistry, Cambridge, UK, 1999. 
[3] K. C. Preethi, C. K. K. Nair, and R. Kuttan, "Clastogenic potential of Ruta graveolens extract and a homeopathic preparation in mouse bone marrow cells," Asian Pacific Journal of Cancer Prevention, vol. 9, no. 4, pp. 763-769, 2008.

[4] S. Pathak, A. Multani, P. Banerji, and P. Banerji, "Ruta 6 selectively induces cell death in brain cancer cells but proliferation in normal peripheral blood lymphocytes: a novel treatment for human brain cancer," International Journal of Oncology, vol. 23, no. 4, pp. 975-982, 2003.

[5] K. Preethi, G. Kuttan, and R. Kuttan, "Anti-tumour activity of Ruta graveolens extract," Asian Pacific Journal of Cancer Prevention, vol. 7, no. 3, pp. 439-443, 2006.

[6] G. Miliauskas, P. R. Venskutonis, and T. A. van Beek, "Screening of radical scavenging activity of some medicinal and aromatic plant extracts," Food Chemistry, vol. 85, no. 2, pp. 231-237, 2004.

[7] X. Liu, M. Zhao, J. Wang, B. Yang, and Y. Jiang, "Antioxidant activity of methanolic extract of emblica fruit (Phyllanthus emblica L.) from six regions in China," Journal of Food Composition and Analysis, vol. 21, no. 3, pp. 219-228, 2008.

[8] M. Gulluce, M. Sokmen, D. Daferera et al., "In vitro antibacterial, antifungal, and antioxidant activities of the essential oil and methanol extracts of herbal parts and callus cultures of Satureja hortensis L," Journal of Agricultural and Food Chemistry, vol. 51, no. 14, pp. 3958-3965, 2003.

[9] E. N. Frankel and A. S. Meyer, "The problems of using onedimensional methods to evaluate multifunctional food and biological antioxidants," Journal of the Science of Food and Agriculture, vol. 80, no. 13, pp. 1925-1941, 2000.

[10] R. Diwan and N. Malpathak, "Histochemical localization in Ruta graveolens cell cultures: elucidating the relationship between cellular differentiation and furanocoumarin production," In Vitro Cellular and Developmental Biology, vol. 46, no. 1, pp. 108-116, 2010.

[11] R. Diwan and N. Malpathak, "Novel technique for scaling up of micropropagated Ruta graveolens shoots using liquid culture systems: a step towards commercialization," New Biotechnology, vol. 25, no. 1, pp. 85-91, 2008.

[12] V. Singleton, R. Orthofer, and R. Lamuela-Raventos, "Analysis of total phenols and other oxidation substrates and antioxidants by means of Folin-Ciocalteu reagent," in Methods in Enzymology, L. Packer, Ed., vol. 299, pp. 152-315, Academic Press, San Diego, Calif, USA, 1999.

[13] M. R. Szabo, C. Idiţoiu, D. Chambre, and A. X. Lupea, "Improved DPPH determination for antioxidant activity spectrophotometric assay," Chemical Papers, vol. 61, no. 3, pp. 214-216, 2007.

[14] C. Teow, V. Truong, R. McFeeters, R. Thompson, K. Pecota, and C. Yencho, "Antioxidant activities, phenolic and $\beta$ carotene contents of sweet potato genotypes with varying flesh colours," Food Chemistry, vol. 103, no. 3, pp. 829-838, 2007.

[15] P. Prieto, M. Pineda, and M. Aguilar, "Spectrophotometric quantitation of antioxidant capacity through the formation of a phosphomolybdenum complex: specific application to the determination of vitamin E," Analytical Biochemistry, vol. 269, no. 2, pp. 337-341, 1999.

[16] M. Oyaizu, "Studies on products of the browning reaction. Antioxidative activities of browning reaction products prepared from glucosamine," Japanese Journal of Nutrition, vol. 44, no. 6, pp. 307-315, 1986.

[17] L. Marcocci, J. Maguire, M. Droy-Lefaix, and L. Packer, "The nitric oxide-scavenging properties of Ginkgo biloba extract EGb 761," Biochemical and Biophysical Research Communications, vol. 201, no. 2, pp. 748-755, 1994.
[18] A. Karagozler, B. Erdag, Y. Emek, and D. Uygun, "Antioxidant activity and proline content of leaf extracts from Dorystoechas hastate," Food Chemistry, vol. 111, pp. 400-447, 2008.

[19] X. Piao, I. Park, S. Baek, H. Kim, M. Park, and J. Park, "Antioxidative activity of furanocoumarins isolated from Angelicae dahuricae," Journal of Ethnopharmacology, vol. 93, no. 2, pp. 243-246, 2004.

[20] I. Grzegorczyk, A. Matkowski, and H. Wysokinska, "Antioxidant activity of extracts from in vitro cultures of Salvia officinalis L," Food Chemistry, vol. 104, no. 2, pp. 536-541, 2007.

[21] F. Borges, F. Roleira, N. Milhazes, L. Santana, and E. Uriarte, "Simple coumarins and analogues in medicinal chemistry: occurrence, synthesis and biological activity," Current Medicinal Chemistry, vol. 12, no. 8, pp. 887-916, 2005.

[22] I. Kostova, "Synthetic and natural coumarins as cytotoxic agents," Current Medicinal Chemistry, vol. 5, no. 1, pp. 29-46, 2005.

[23] R. Marwah, M. Fatope, R. Al Mahrooqi, G. B. Varma, H. Al Abadi, and S. Al-Burtamani, "Antioxidant capacity of some edible and wound healing plants in Oman," Food Chemistry, vol. 101, no. 2, pp. 465-470, 2007. 

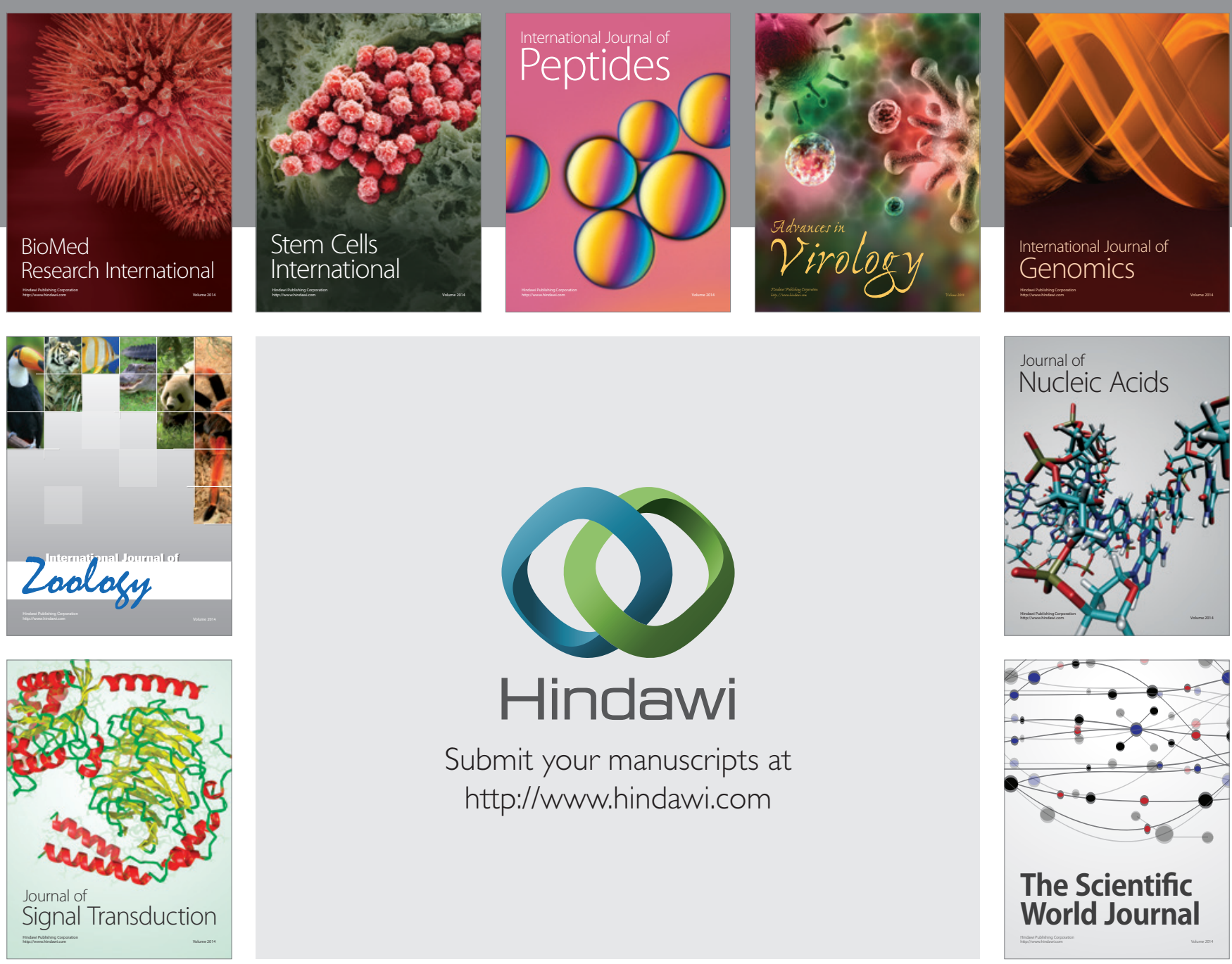

Submit your manuscripts at

http://www.hindawi.com
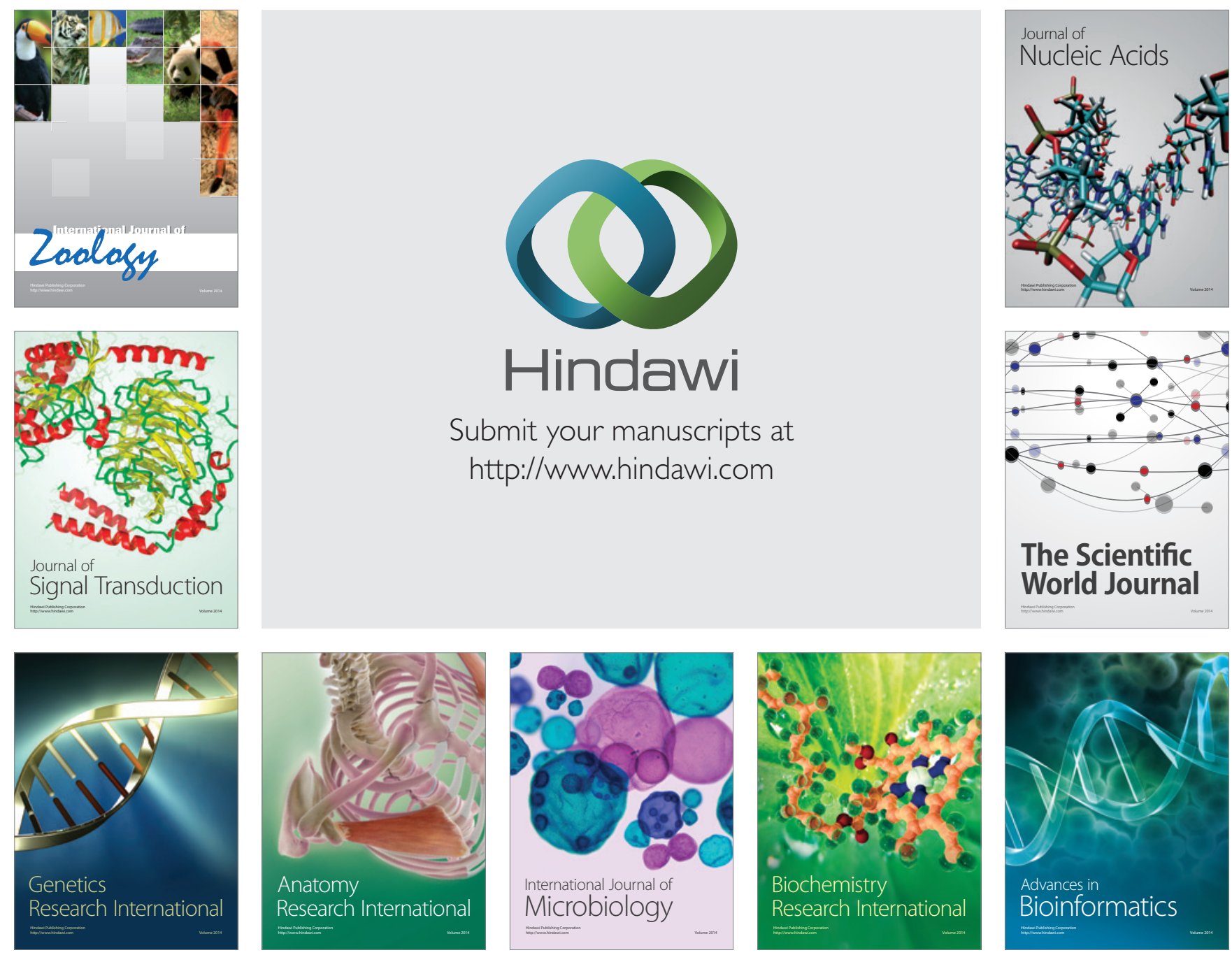

The Scientific World Journal
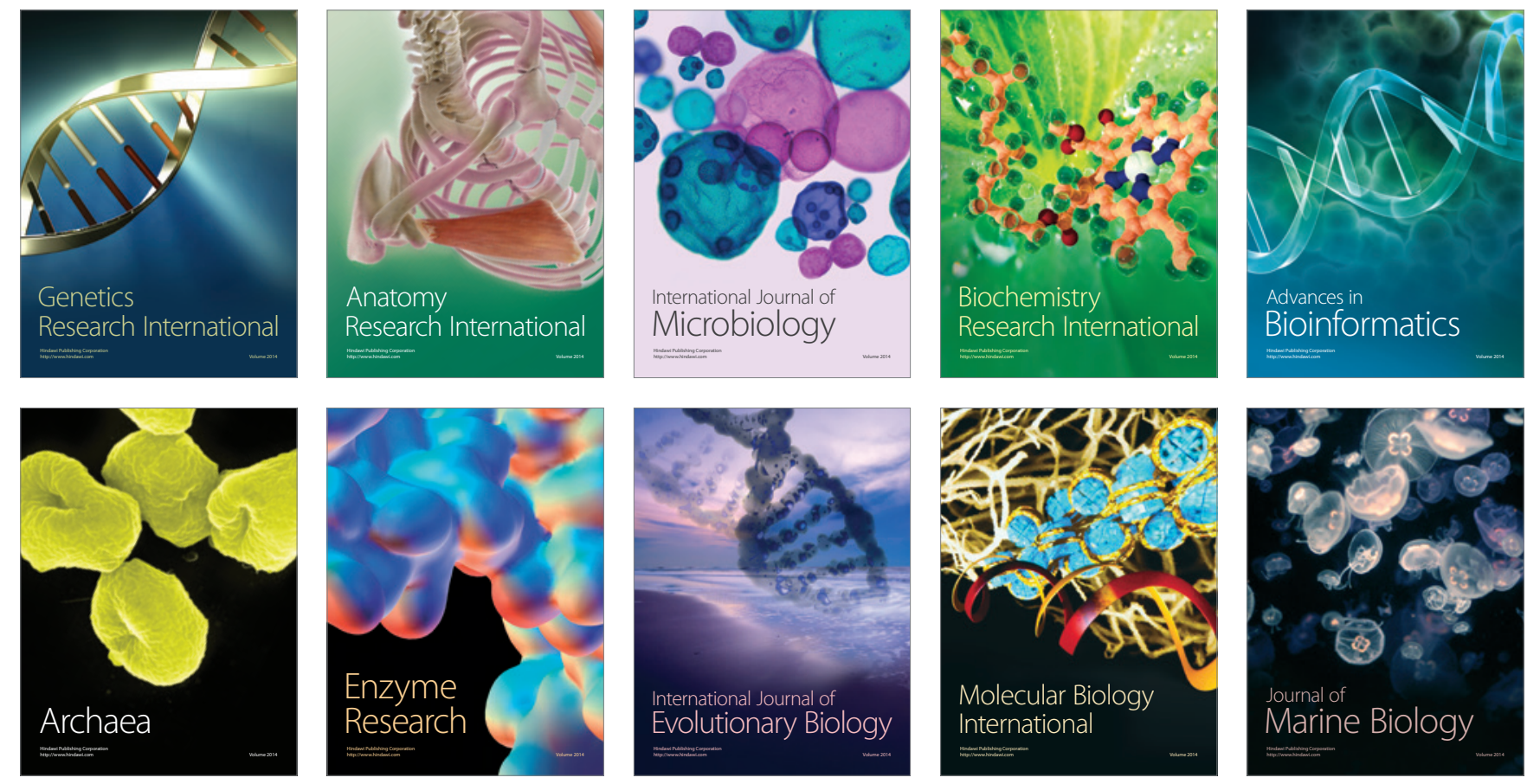